\title{
ENHANCEMENT OF VOLTAGE STABILITY CONSIDERING EFFECTS OF WTG AND LOAD UNCERTAINTIES USING DIFFERENTIAL EVOLUTION
}

\author{
Namami Krishna Sharma ${ }^{1}$, Aishwarya Varma ${ }^{2}$, S. C. Choube \\ ${ }^{I}$ Department of Electrical \& Electronics engineering, UIT-RGPV, Bhopal, India \\ ${ }^{2}$ Department of Electrical \& Electronics engineering, UIT-RGPV, Bhopal, India \\ ${ }^{3}$ Department of Electrical \& Electronics engineering, UIT-RGPV, Bhopal, India
}

\begin{abstract}
This paper focuses on the improvement of voltage stability under the presence of various load uncertainties and WTG. Incorporation of WTG and ambiguous load variations are accounted here. The violation in stability limits due to uncertainties have been limited by designing the constrained objective function to improve voltage stability margin and in turn reduce active and reactive power losses. A multi objective problem is designed to minimize voltage deviation and power losses while satisfying the operating constraints, in order to enhance the system stability pertaining to uncertain environment. Primarily, a dynamic load flow program is formed to incorporate the data uncertainty at load buses. The adverse case affecting system stability is identified by the case having least Eigen value of the Jacobean matrix. L-index is calculated for all the buses of the identified case to decide the placement of Static VAR Compensator (SVC). The SVC operates as a control variable to enhance the systems voltage stability. Lastly, Differential Evolution (DE) Algorithm is used to obtain optimal value of SVC. The results are validated with the help of other optimization techniques namely, Black Hole Algorithm (BHA) and Particle Swarm Optimization (PSO). IEEE-14 bus system is used to implement the aforementioned problem.
\end{abstract}

Keywords: - WTG; Uncertainty; L-index; Static VAR Compensator; Differential Evaluation

\section{NOMENCLATURE}

\section{Abbreviations}

WTG Wind Turbine Generator

DG Distributed Generation

DE Differential Evaluation

BHA Black Hole Algorithm

PSO Particle Swarm Optimization

SVC Static VAR Compensator

PU Per Unit

PDF Probability Density Function

LVSI Line voltage stability index

PCM Participation factor

\section{Notations}

eig Minimum Eigen value

J Load flow Jacobean Matrix

$\zeta \quad$ Mutation constant

$\underline{V}_{i}^{(k)} \quad$ Mutant vector

$\mathrm{C}_{\mathrm{r}} \quad$ Crossover Probability

$\mathrm{t}_{\mathrm{i}} \quad$ Trial Vector

$\mathrm{X}_{\mathrm{i}} \quad$ Target Vector

\section{Parameters}

$\mathrm{N} \quad$ Normal Distribution

exp Exponential Distribution $\mathrm{db} \quad$ Deviation from Base Case

$\psi \quad$ Uncertain load adjustment factor either $\{\mathrm{N} / \exp /$ $\mathrm{db}\}$

$\xi \quad$ Output uncertainties on the unknown quantities which is a combined effect of $(\mathrm{N}, \exp , \mathrm{db})$

$\mu \quad$ Mean Value

$\sigma \quad$ Standard Deviation

b Load regulating parameter

$\lambda$ Parameter used for deviation from base case load

\section{Constants}

$P_{D i}^{0} \quad$ Base case real power load at $\mathrm{i}^{\text {th }} \mathrm{PQ}$ bus in MW

$Q_{D i}^{0} \quad$ Base case reactive power load at $\mathrm{i}^{\text {th }} \mathrm{PQ}$ bus in MVAR

$\Phi \quad$ Power Factor angle of WTG in degree

$\rho_{\mathrm{a}} \quad$ Air density in $\mathrm{kg} / \mathrm{m}^{3}(1.225)$

A Cross sectional area of wind turbine $\mathrm{m}^{2}$

$\mathrm{C}_{\mathrm{P}} \quad$ Turbine coefficient (0.5926)

$\mathrm{v}_{\mathrm{r}} \quad$ Rated speed of wind $(11 \mathrm{~m} / \mathrm{s})$

$\mathrm{v}_{\text {cut in }}$ Cut-in speed of wind $(3.5 \mathrm{~m} / \mathrm{s})$

$\mathrm{v}_{\text {cut out }}$ Cut-out speed of wind $(20 \mathrm{~m} / \mathrm{s})$

$\mathrm{G}_{\mathrm{k}} \quad$ Conductance of line $\mathrm{k}$ in P.U.

$\mathrm{Y}_{\mathrm{ij}} \quad$ Magnitude of the admittance of the line connected between $\mathrm{i} \& \mathrm{j}$ in $\mathrm{pu}$

$\theta_{\mathrm{ij}} \quad$ Angle associated to $\mathrm{Y}_{\mathrm{ij}}$ in degree

$\mathrm{V}_{\mathrm{i} \text { min }} \quad$ Minimum value of pu voltage magnitude at $\mathrm{i}^{\text {th }}$ bus 
$\mathrm{V}_{\mathrm{i} \max } \quad$ Maximum value of pu voltage magnitude at $\mathrm{i}^{\text {th }}$ bus

$\mathrm{Q}_{\mathrm{Gi} \text { min }}$ Minimum value of reactive power generated at $i^{\text {th }}$ generator bus

$\mathrm{Q}_{\mathrm{Gi} \text { min }}$ Maximum value of reactive power generated at $\mathrm{i}^{\text {th }}$ generator bus

$\mathrm{Q}_{\mathrm{Gsh}}$ i min Minimum value of reactive power provided by shunt compensation at $i^{\text {th }}$ bus

$\mathrm{Q}_{\text {Gsh i max }}$ Maximum value of reactive power provided by shunt compensation at $i^{\text {th }}$ bus

\section{Variables}

$|V| \quad$ Voltage magnitude in P.U.

$\delta \quad$ Voltage angle in degree

$\mathrm{P}_{\mathrm{Di}}(\psi) \quad$ Uncertain Real Power load at $\mathrm{i}^{\text {th }} \mathrm{PQ}$ bus

$\mathrm{P}_{\mathrm{Di}}(\psi) \quad$ Uncertain Reactive Power load at $\mathrm{i}^{\text {th }} \mathrm{PQ}$ bus

$P_{\text {WTGi }} \quad$ Real Power output of WTG placed at $i^{\text {th }}$ PQ bus

$\mathrm{Q}_{\text {WTGi }}$ Reactive Power drawn by WTG at it PQ bus

$\boldsymbol{P}_{D i}^{\prime} \quad$ Effective Real Power loading at $\mathrm{i}^{\text {th }} \mathrm{PQ}$ bus which is selected for placement of WTG

$Q_{D i}^{\prime} \quad$ Effective Reactive Power loading at $\mathrm{i}^{\text {th }} \mathrm{PQ}$ bus which is selected for placement of WTG

$\mathrm{v} \quad$ Wind velocity in meter/sec

$\mathrm{V}_{\mathrm{k}}^{\xi} \quad$ Voltage magnitude at kth PQ bus after incorporating $\psi$ uncertainties in input parameters

$\mathrm{V}^{0}{ }_{\mathrm{k}} \quad$ Voltage magnitude at kth PQ bus in base case

$\delta_{k}^{i} \quad$ Voltage angle at $i^{\text {th }}$ bus after inclusion of the effect of uncertainties in input parameters

$P_{G i}^{\xi} \quad$ Active Power generation in MW at ith bus due to the effect of uncertainties in input

$Q_{G i}^{\xi} \quad$ Reactive Power generation in MVAR at ith bus due to the effect of uncertainties in input

$\mathrm{P}_{\text {Loss }} \quad$ Real power losses in MW

Q Loss Reactive power losses in MVAR

$\mathrm{V}^{\xi}{ }_{\mathrm{i}} \quad \mathrm{i}^{\text {th }}$ bus voltage magnitude in per unit due to uncertain inputs

$\mathrm{Q}_{\mathrm{Gsh}}$ Reactive power provided by $\mathrm{SVC}$ at $\mathrm{i}^{\text {th }}$ bus in MVAR

$\Delta Q_{G i}^{r e s}$ Technical reactive reserves in MVAR

\section{INTRODUCTION}

The foremost purpose of the electrical power system is to transfer electrical power from the generator stations to the consumer end. With the intention to have appropriate functioning of the power systems, it is essential that the voltage is kept close to nominal value in the entire power system. Modern power systems are operating under stressed condition and the stability margin may thus become inadequate. In such situation, uncertainty in input parameters affects the transfer capability of the system. Thus, probabilistic risk of transferring a certain amount of load becomes an important concern. The planning and design of power system mostly bank upon deterministic approach by the utilities. The drawback of deterministic approach is that it does not account for the inherent random nature of the resources at site, system behaviour and customer requirements etc. Factors causing uncertainty are increasing with the restructuring of the utilities. In modern power systems especially, inaccuracies and uncertainties leads to aberrations in planning and operation. This makes the analysis of uncertainties in power systems operation necessary. Available control measures must be utilized to ensure safe, secure and reliable operation of the system. Sources of uncertainty include fuel price, generation availability, transmission capacity, market rules, market forces, energy price, load requirement, unplanned outages, weather and other interruptions, etc. the short comings of deterministic approach can be overcome by probabilistic approach, which incorporates the inherent uncertainties in the factors. Power system designers and planners sometimes find it difficult to interpret these uncertainties using reliability indices based on stochastic nature of the system. This complexity can be alleviated by integrating deterministic evaluation in probabilistic environment using well-being concept.

The estimation and representation of the influence of uncertainty are major concern for analysis of the complexity in system [1, 2]. With lesser reserves and increasing uncertainties than in the past, modern power systems are forced to operate near closer to security margins. Factual evidences are a proof of blackouts throughout the world [3]. Techniques for sensitivity and uncertainty analysis are precisely presented in [2] using Monte Carlo analysis, response surface analysis, differential analysis, Fourier amplitude sensitivity test, fast probability integration and Sobol's variance decomposition. Dynamic analysis method of small signal method $[4,5]$ and simulation methods based on time domain $[6,7]$ are used to address the dynamic problem of voltage instability. A computational feasible method to assess impact of uncertainties due to dynamic behaviour of power system in simulation is shown in [8]. A newly developed Differential Evolution computing technique is proposed in [9] which holds better accuracy and lesser time for convergence. Particle Swarm Optimization is another technique applied on engineering problems, inspired from nature. Black Hole optimization technique proposed in [10] is the modified form of PSO is finding significant attention at present.

This paper presents voltage stability analysis, carried out with due consideration of WTG and variation in load parameters. The cases presented in section 2 have been studied and the same have been incorporated in our work. Three different load models are used namely, normally distributed, exponentially distributed and deviation from base loading at different buses. Uncertain model of WTG is designed based on practical data of wind velocity. The minimum Eigen value of the Jacobian matrix in load flow is obtained for all the incorporated uncertainties. The critical Eigen value determines the stability probability of a power system. Stability margin is deduced from critical loading level, i.e. the loading at which system is 'probabilistically' stable. DE is employed to find optimum value of control variable which satisfies the objective function, i.e. minimum voltage deviation and loss minimization, subjected to 
uncertain inputs. The results obtained are compared with other optimization techniques like Particle Swarm Optimization (PSO) and Black Hole Algorithm (BHA).The objectives of this paper are to provide probability density function (PDF) on input data and find the PDF on output data. Find healthy and critical mode of operation based on dynamic systems' Eigen value, with respect to critical case compute the most effective control action to boost reactive power reserve in the system and hence to improve voltage stability by determining the optimal value of control variable and reduce overall losses.

This paper is organized as follows: The uncertain load models and WTG model is present in section II. Section III gives overview of DE, PSO and BHA. Section IV provides the problem formulation followed by methodology in section V. Section VI presents the results of proposed method and its comparison with various techniques and the conclusion is given in section VII.

\section{UNCERTAIN LOAD AND WTG MODELLING}

Numerous ambiguities are present in power system operation. One of them is dynamic variation in load parameter, which affects voltage stability margin assessment [11]. For the same load model, different ranges are presented in [6, 13]. It is largely accepted that in power system electrical loads obey normal distribution when long term uncertainties are considered [14]. Traditionally, static load models were applied to power system for stability evaluation. After exponential recovery load models [15] and adaptive load models [16], dynamic load models were introduced to study about voltage stability. For analysing the load variation in a day, we have divided 24 hours into 48 subsections.

Uncertain load can be represented by probabilistic distributions functions and/or deviation by some scaling parameters. All the load models used in this paper are presented in section 2, namely normally distributed load, exponential load and deviation from base case have been used for load variations at the buses mentioned in the same section.

\subsection{Normal Distribution representation of}

\section{Uncertain Load}

The general formula for the probability density function of the normal distribution for uncertain load $P_{D}$ is [14,27],

$$
\begin{aligned}
& f\left(P_{D}\right)=\frac{e^{\frac{\left(P_{D}-\mu\right)^{2}}{2 \sigma^{2}}}}{\sigma \sqrt{2 \Pi}} \\
& -\infty \leq P_{D} \leq \infty \\
& \sigma>0
\end{aligned}
$$

The normally distributed real power load modelling is done as follows:

$$
P_{D i}\left(\Psi_{N}\right)=\operatorname{Normrnd}(\mu, \sigma, m, n)
$$

Normally distributed real power load is at bus $i=4$ with $\mu=40$ and $\sigma=10$, and $\mathrm{m}, \mathrm{n}$ is a $(48 \times 1)$ array. The normally distributed real power load variation at load bus no. $i=4$ is shown in figure 1 and corresponding histogram representation is shown in figure 2 .

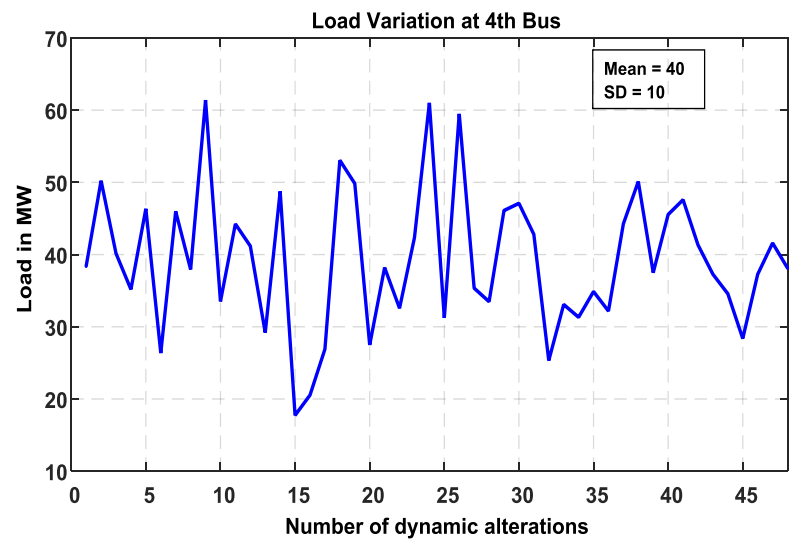

Fig 1: Variation of load w.r.t. time

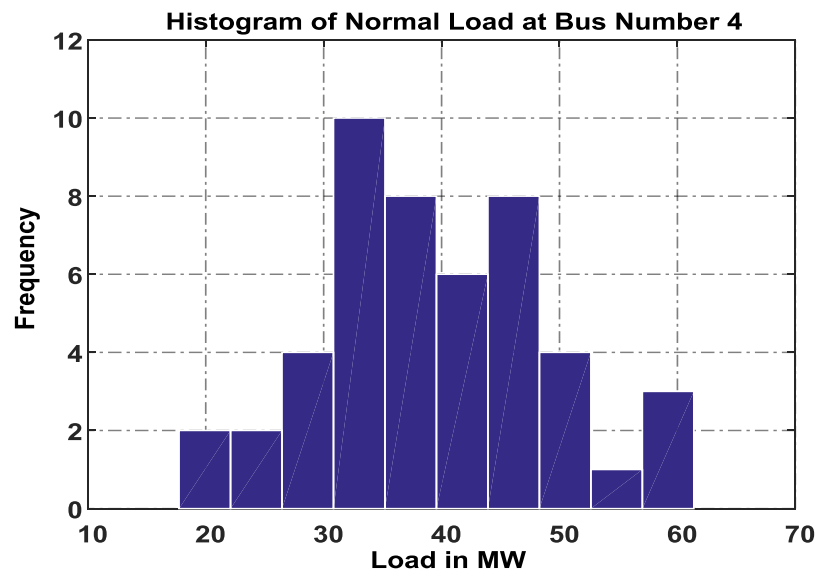

Fig 2: Histogram of load variation

\subsection{Exponential Distribution of Uncertain Load}

The formula for the probability density function of the exponential distribution for uncertain load $P_{D}$ is [27],

$$
\begin{aligned}
& f\left(P_{D}\right)=\frac{e^{-\frac{\left(P_{D}-\mu\right)}{b}}}{b} \\
& P_{D} \geq \mu \\
& b>0
\end{aligned}
$$

Here the exponential distributed real power load modelling is done as follows,

$$
P_{D i}\left(\Psi_{\exp }\right)=P_{D i}^{0}+\frac{\exp \frac{(x-\mu)}{b}}{b}
$$


Exponential rising real power load at bus $i=5$

with $\mathrm{x}=$ linearly spaced numbers between $\left(0-P_{D 5}^{0}\right)$

$\mu=\operatorname{mean}(\mathrm{x})$ and $\mathrm{b}=1.8$

The variation of exponential distribution real power load at $\mathrm{i}=5$ PQ bus is shown in figure 3 and corresponding PDF is shown in figure 4.

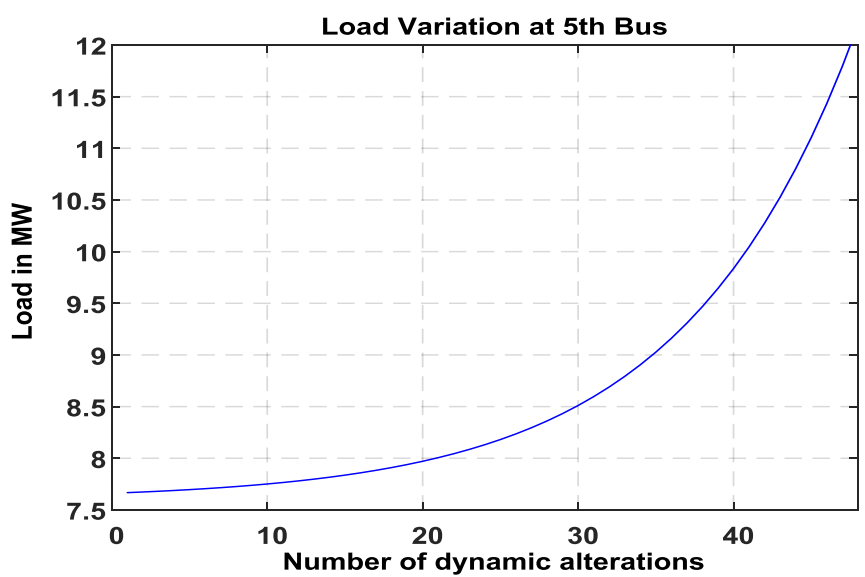

Fig 3: Variation of load w.r.t. time

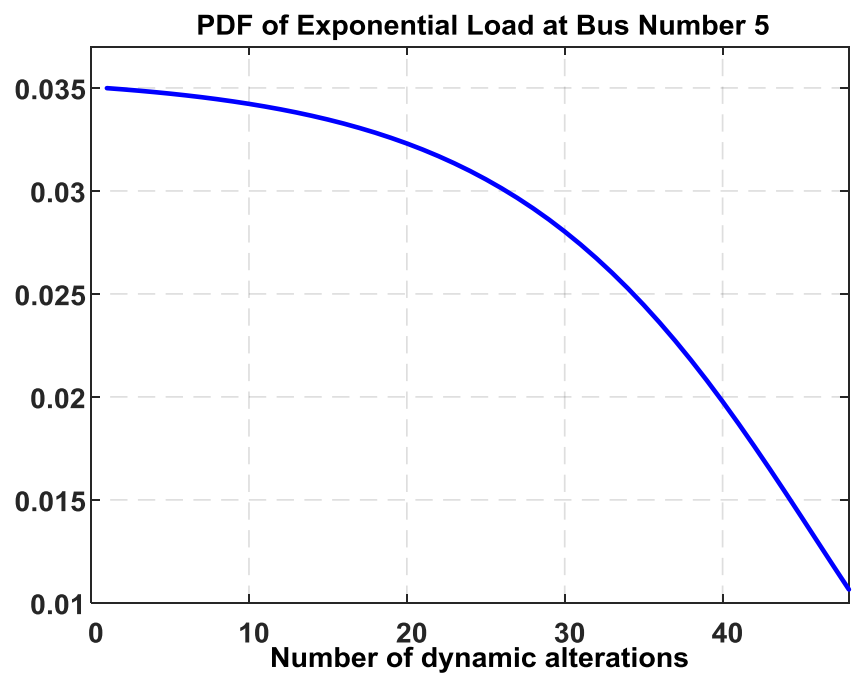

Fig 4: PDF of exponentially distributed load

\subsection{Deviation from Base Case Loading of Uncertain}

\section{Load}

Bus number 10 is selected for deviation from base case load modelling [27]. For real power loading the load varies from 0 to $150 \%$ of rated load and for reactive power loading it varies from 0 to $150 \%$ of rated reactive load which can be represented as follows:

\section{(i) Real Power Loading}

$$
P_{D i}\left(\Psi_{d b}\right)=P_{D i}^{0}(1+\lambda)
$$

Deviation from base case loading in real power demand at bus $\mathrm{i}=10$ with $\lambda=$ scaling parameter (linearly spaced numbers between -1 to 0.5$)$. Variation w.r.t. time is shown in figure 5 and corresponding PDF is shown in figure 6.

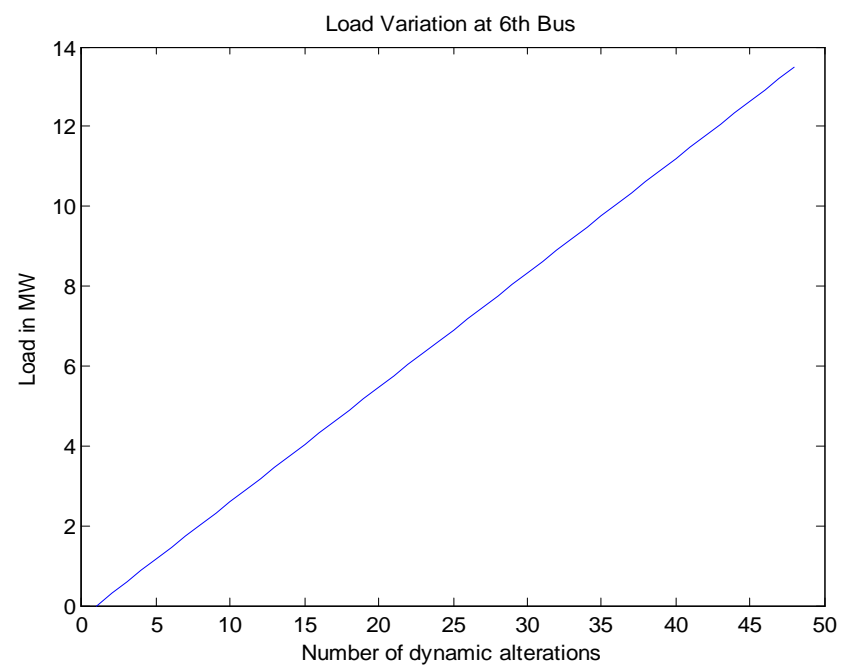

Fig 5: Variation of real power load w.r.t. time

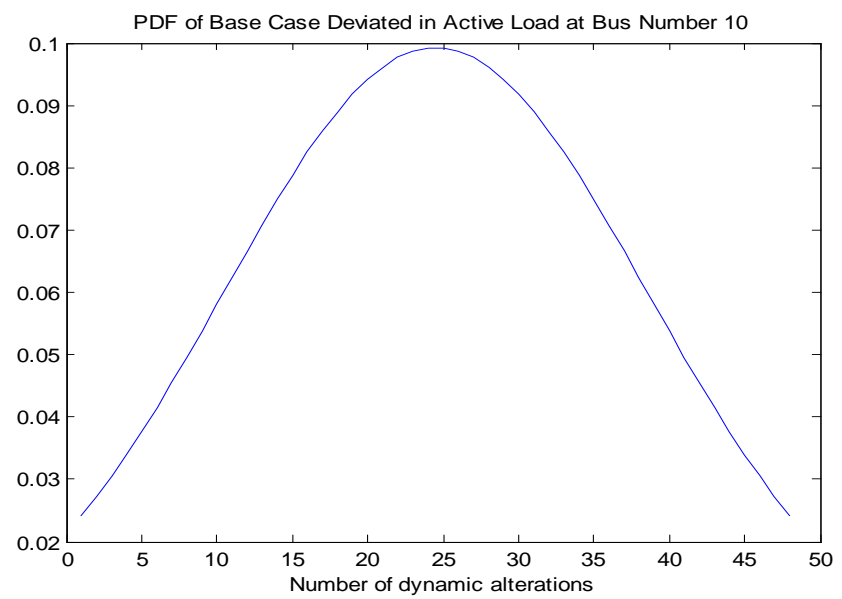

Fig 6: PDF of real power load variation

(ii) Reactive Load Modelling

$$
Q_{D i}\left(\Psi_{d b}\right)=Q_{D i}^{0}(1+\lambda)
$$

Deviation from base case loading in reactive power demand at bus $\mathrm{i}=10$ with $\lambda=$ scaling parameter (linearly spaced numbers between -1 to 0.5 ). Variation w.r.t. time is shown in figure 7 and corresponding PDF is shown in figure 8. 


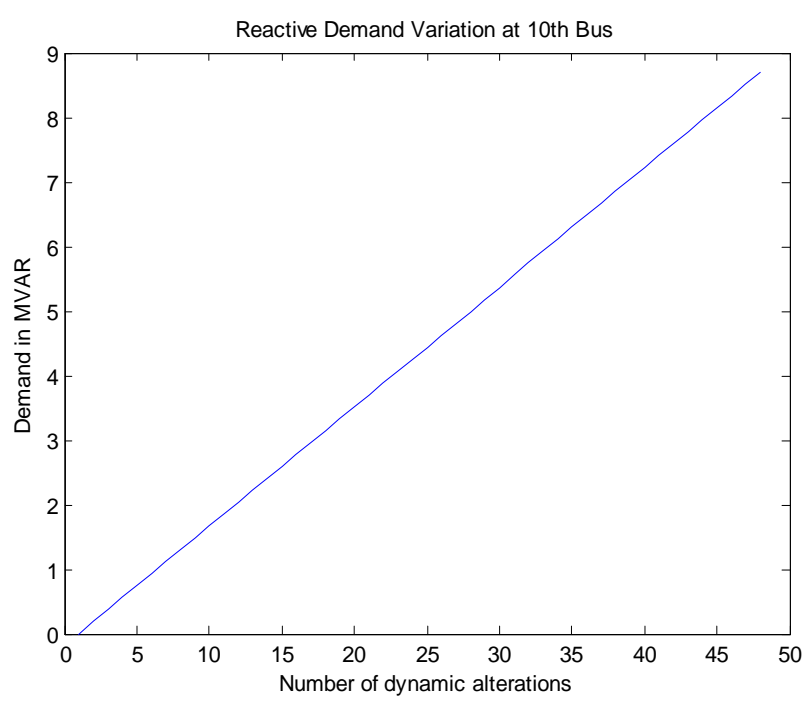

Fig 7: Variation of load w.r.t. time

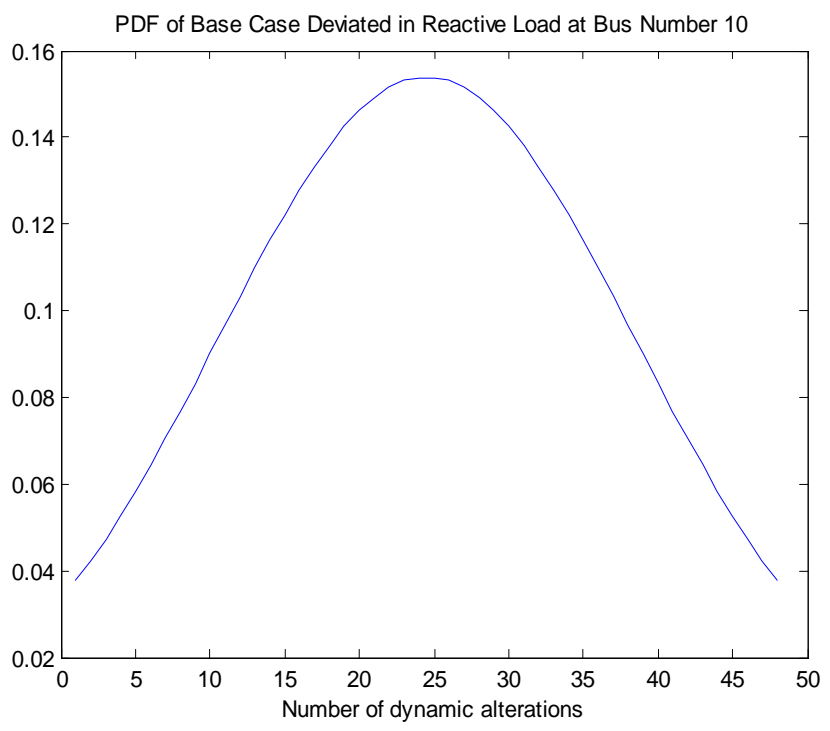

Fig 8: PDF of load variation

\subsection{Modelling of Wind Turbine Generator}

Wind power plants as well as other variable sources such as solar and tidal sources have very low operating costs. They are usually assumed to be zero therefore these power plants are at the top of the merit order. While talking about distributed generation our focus was mainly put on generation through wind turbines connected at load ends. It has lately been observed that wind farms are being directly connected to the transmission line. Network having connected wind farms will have more fluctuations in power flows along with load variations. Here, Wind Turbine Generators are modelled as loads only which are capable of feeding active power in the system while consuming reactive power from the system [28]. The wind farms are not a major source of frequency variation since they take reactive power from the grid which rises the risk of voltage instability. The reactive power consumption of wind farms has an important influence on power system consequently wind turbine influences the steady state voltage of the grid. The wind farms affect the power flows and hence the node voltages. Performance of wind farms can be measured by power quality measures, load flow criteria, grid stability issue, and relay coordination problems. The basic challenges regarding the network integration of wind power consists therefore of the following steps,

1. How to keep acceptable voltage level for all consumers

2. How to keep power balance of the system.

In the active distribution network active management of voltage control is required but since the penetration level is low the voltage control policy designed for passive network can be used. In our case since we have designed a dynamic WTG model the penetration level keeps on changing and its maximum value is $2.66 \%$ of total rated real power loading. A simplified wind power generation model for reliability evaluation is presented in [17]. Modelling of WTG is presented in [18]. Here practical values of wind flow are considered for WTG modelling. It supplies real power output to the grid in two ways from cut in velocity to rated velocity of wind, the real power output is the direct function of wind velocity and turbine parameters and from rated speed to cut-out speed of wind the real power output is constant irrespective of wind velocity which can be seen in figure 9. The cut in speed is $3.5 \mathrm{~m} / \mathrm{sec}$, rated speed is $11 \mathrm{~m} / \mathrm{sec}$ and cut out is $20 \mathrm{~m} / \mathrm{sec}$. Wind turbine with an induction generator connected directly to the grid consumes reactive power as a function of the output real power and the operating power factor is assumed to be constant $(0.85 \mathrm{lag})$. The consumption is typically compensated by the system. It is considered that wind speed is changing in every half an hour, that's why 48 sub sections are taken over 24 hours. Candidate buses for WTG are 4 and 7 obtained by L-index mentioned in section VI. The positive impacts of WTG are Voltage and reactive power support, Voltage control, Reduction of losses and transmission blocking, Generation growth and better utilization of assets, Improvement of reliability by ensuring continuity of supply and the negative impacts of WTG are: increase in short circuit current, drop of sensitivity to faults, voltage rise and fluctuations, changes in losses and voltage profile, frequency and voltage instability.

$$
\begin{gathered}
P_{D i}^{\prime}=P_{D i}^{0}-P_{W T G i}^{\prime} ; P_{W T G i}^{\prime} \leq 9 M W \\
Q_{D i}^{\prime}=Q_{D i}^{0}+P_{W T G i}^{\prime} \operatorname{Tan} \phi ;
\end{gathered}
$$

$\operatorname{Cos} \Phi=0.85$ lagging

$$
P_{W T G i}^{\prime}=\left\{\begin{array}{l}
\frac{1}{2} \rho_{a} A v^{3} C_{p} ; \quad v_{\text {cutin }} \leq v_{\text {rated }} \\
7.136 M W ; \quad v_{\text {rated }} \leq v \leq v_{\text {cutout }}
\end{array}\right.
$$

The real and reactive power variation of the WTG connected to load end are shown in figure 9 to 11 . 


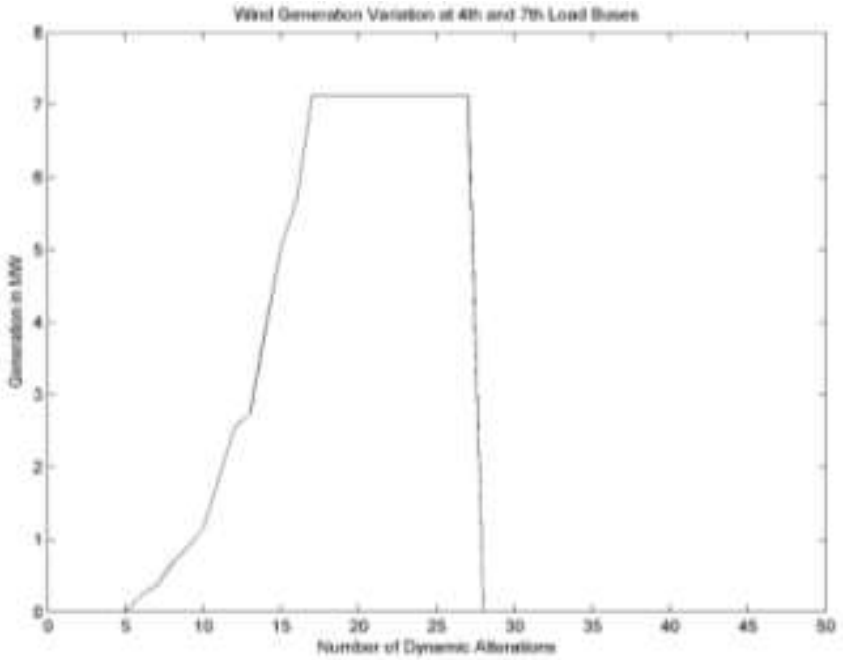

Fig 9: Real power output from WTG at bus 4 and 7

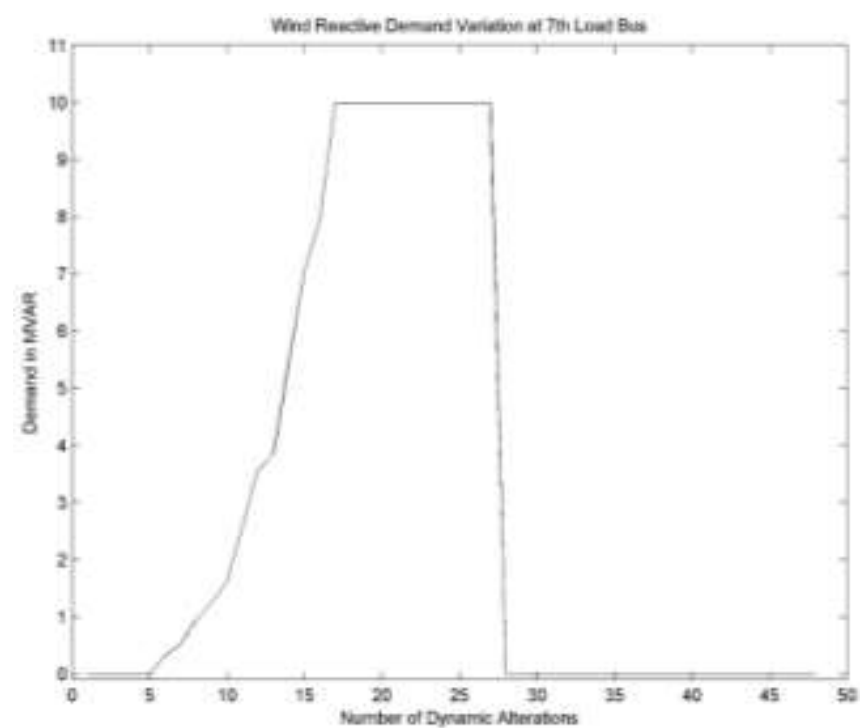

Fig 10: Reactive power drawn from WTG at bus 4

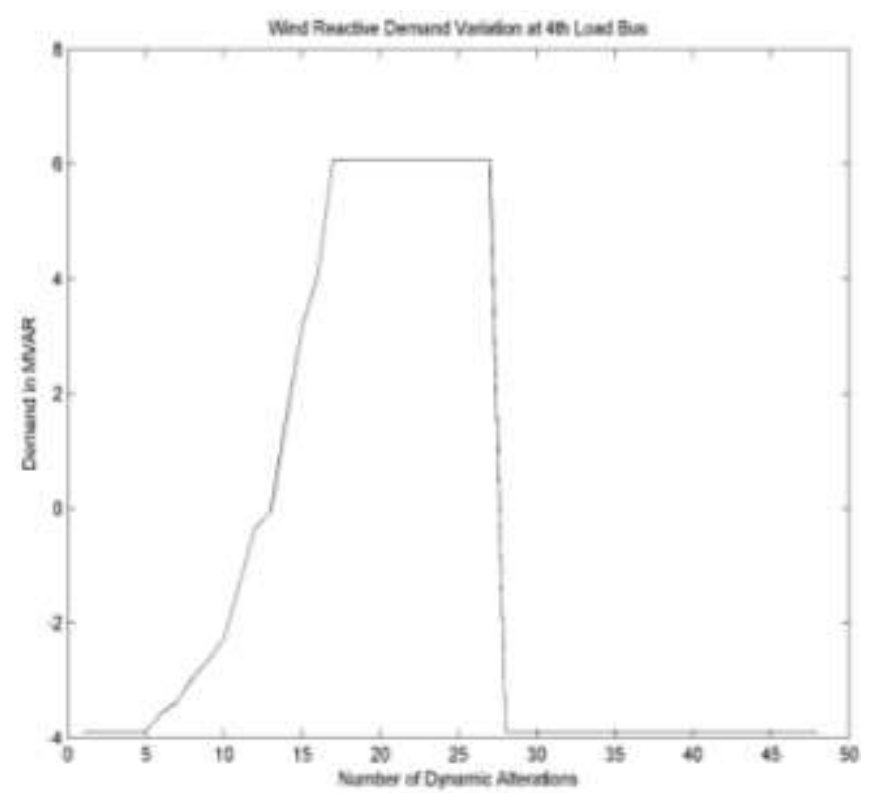

Fig 11: Reactive power drawn from WTG at bus 7

\section{OVERVIEW OF DE, BHA AND PSO}

\subsection{Differential Evolution ' $D E$ '}

DE algorithm is population based algorithm using three operators; crossover, mutation and selection to solve realparameter optimization problems [21]. Differential mutation adds a scaled, randomly sampled, vector difference to a third vector as follows,

$$
\underline{V}_{i}^{(k)}=X_{r 1}^{(k)}+\sigma\left(X_{r 2}^{(k)}-X_{r 3}^{(k)}\right)
$$

where $\underline{V}_{i}^{(k)}$ is a mutant vector and $X_{r}^{(k)}$ is population of $\mathrm{r}^{\text {th }}$ particle at $\mathrm{k}^{\text {th }}$ generation and $\sigma$ is the mutant parameter. DE employs a uniform crossover strategy. Crossover generates trial vectors $\boldsymbol{t}_{i, j}{ }^{(k)}$ as follows.

$$
t_{i, j}^{(k)}=\left\{\begin{array}{lr}
v_{i, j}^{(k)} & \text { if }\left(\text { rand }_{j} \leq C_{r} \text { or } j=j_{\text {rand }}\right) \\
x_{i, j}^{(k)} & \text { otherwise }
\end{array}\right.
$$

$\mathrm{C}_{\mathrm{r}}$ is crossover probability lies in the range $[0,1] . \mathrm{C}_{\mathrm{r}}$ is user defined value which controls the number of parameter values which are copied from the mutant. If the random number rand is less than or equal to $\mathrm{C}_{\mathrm{r}}$, the trial parameter is adopted from the mutant. Further, the trial parameter with randomly chosen index, rand is taken from the mutant to ensure that trial vector does not duplicate target vector. Otherwise the parameter is adopted from the target vector. Objective function is evaluated for target vector and trial vector, trial vector is selected if it provides better value of the function than target vector as follows:

$$
X_{i}^{(k+1)}=\left\{\begin{array}{lr}
t_{i}^{(k)} & \text { if } f\left(t_{i}^{(k)}\right) \leq f\left(X_{i}^{(k)}\right) \\
X_{i}^{(k)} & \text { otherwise }
\end{array}\right.
$$

$$
\begin{aligned}
& v_{i, j}^{(k)}=x_{r 1, j}+\left(x_{j, \min }-x_{r 1, j}\right) \operatorname{rand}(0,1), \text { if } v_{i, j}^{(k)} \leq x_{j, \min } \\
& v_{i, j}^{(k)}=x_{r 1, j}+\left(x_{j, \max }-x_{r 1, j}\right) \operatorname{rand}(0,1), \text { if } v_{i, j}^{(k)} \geq x_{j, \max }
\end{aligned}
$$

\subsection{Black Hole Algorithm 'BHA'}

Black Hole technique was developed by A. Hatamlou [11], inspired by the black hole phenomenon. The BH algorithm is a population based method. In BHA, the evolution of population is done by moving all the candidates towards the best candidate in each iteration, namely, the black hole. In addition, there is the probability of crossing the event horizon during moving stars towards the black hole. Every star (candidate solution) that crosses the event horizon of the black hole will be sucked by the black hole. The absorption of stars by the black hole is formulated as follows: 


$$
\begin{gathered}
x_{i}(t+1)=x_{i}(t)+\operatorname{rand}\left(x_{B H}-x_{i}(t)\right) \\
i=1,2, \ldots N
\end{gathered}
$$

where, $x_{i}(t)$ and $x_{i}(t+1)$ are the locations of the $i^{\text {th }}$ star at iterations ' $t$ ' and ' $t+1$ ', respectively. ' $x_{\mathrm{BH}}$ ' is the location of the black hole in the search space, 'rand' is a random number in the interval $[0,1], \mathrm{N}$ is the number of stars (candidate solutions). Every time a candidate (star) dies, it is sucked in by the black hole, another candidate solution (star) is born and distributed randomly in the search space and starts a new search. This is done to keep the number of candidate solutions constant. The next iteration takes place after all the stars have been moved. The radius of the event horizon in the black hole algorithm is calculated using the following equation:

$$
R=\frac{f_{B H}}{\sum_{i=1}^{N} f_{i}}
$$

where, ' $f_{\mathrm{BH}}$ ' is the fitness value of the black hole and ' $\mathrm{f}_{\mathrm{i}}$ ' is the fitness value of the $i^{\text {th }}$ star. When the distance between a candidate solution and the black hole (best candidate) is less than $\mathrm{R}$, that candidate is collapsed and a new candidate is created and distributed randomly in the search space.

\subsection{Particle Swarm Optimization 'PSO'}

PSO is a population based optimization tool it was proposed by James Kennedy and Russell Eberhart [20]. System is initialized with a population of particles and algorithm searches for optima by updating generations. Each particle keeps track of its coordinates in hyperspace which are associated with the best solution (fitness) it has achieved so far, called 'Pbest'. Another "best" value is also tracked. The "global" version of the particle swarm optimizer keeps track of the overall best value, and its location, obtained thus far by any particle in the population, called 'Gbest'. The particle swarm optimization concept consists of, at each time step, changing the velocity each particle toward its 'Pbest' and 'Gbest'. Acceleration is weighted by a random term, with separate random numbers being generated for acceleration toward 'Pbest' and 'Gbest'. Velocity and position of each particle in the next generation (time step) can be calculated as:

$$
\begin{aligned}
& V^{i}(t+1)=w^{*} V^{i}(t)+c_{1} * \operatorname{rand}\left(\text { pbest }_{i}-X^{i}{ }_{t}\right) \\
& +c_{2} * \operatorname{rand}\left(\text { gbest }-X^{i}{ }_{t}\right)
\end{aligned}
$$

$$
X^{i}{ }_{(t+1)}=X^{i}{ }_{t}+V^{i}(t+1)
$$

where

$\mathrm{w}=$ Inertia weight of the particle $(0.9-0.4)$

$\mathrm{t}=$ Generation number

$\mathrm{c}_{1}, \mathrm{c}_{2}=$ Acceleration Constant

rand $=$ uniform random value in the range [0-1]

$V^{i}{ }_{t}=$ Velocity of particle $i$ at generation $t$

$X^{i}{ }_{t}=$ Position of particle $i$ at generation $t$

\section{PROBLEM FORMULATION}

A multi objective problem has been formulated with consideration of load uncertainties and WTG. The first objective function is minimum voltage deviation at the load buses and second objective function is minimum real power line losses subjected to uncertain inputs.

\subsection{Objective Functions}

The voltage deviation due to input uncertainties from reference value of voltage magnitude (1 p.u.) should be minimum (15),

$$
\sum_{\forall k}^{N_{P Q}} \min \left|V_{k}^{\xi}-V_{k}^{0}\right|
$$

Network losses, either for the whole of a network or for certain sections and lines, are non-separable functions of dependent and independent variables given by (16),

$$
\sum_{\forall k}^{N_{t}} \min \quad G_{k}\left[\left(V_{i}^{\xi}\right)^{2}-\left(V_{j}^{\xi}\right)^{2}-2 V_{i}^{\xi} V_{j}^{\xi} \operatorname{Cos}\left(\delta_{i}^{\xi}-\delta_{j}^{\xi}\right)\right]
$$

\subsection{Subjected To}

\subsubsection{Equality Constraints}

$$
P_{G i}^{\xi}-P_{D i}^{\Psi}+P_{D W T G i}^{\prime}=\sum_{\forall i}\left|V_{i}^{\xi}\left\|V_{j}^{\xi}\right\| Y_{i j}\right| \operatorname{Cos}\left(\theta_{i j}+\delta_{i}^{\xi}-\delta_{j}^{\xi}\right)
$$

$$
Q_{G i}^{\xi}-Q_{D i}^{\Psi}-Q_{W T G i}^{\prime}=-\sum_{\forall i}\left|V_{i}^{\xi}\left\|V_{j}^{\xi}\right\| Y_{i j}\right| \operatorname{Sin}\left(\theta_{i j}+\delta_{i}^{\xi}-\delta_{j}^{\xi}\right)
$$

(Static load flow equations with consideration of uncertain inputs are modelled as equality constraints).

\subsubsection{Inequality Constraints}

Voltage limit from $0.95 \mathrm{pu}$ to $1.05 \mathrm{pu}$ is one of the inequality constraint, eq. (19)

$$
V_{i \min } \leq V_{i}^{\xi} \leq V_{i \max }
$$


Reactive power generation for all the generators or voltage controlled buses is considered as second inequality constraint with consideration of uncertainty, eq. (20)

$$
Q_{G i \text { min }} \leq Q_{G i}^{\xi} \leq Q_{G i \text { max }}
$$

The uncertainty incorporated in the system is limited by minimum to maximum uncertain load adjustment factor, eq. (21)

$$
\Psi_{\text {min }} \leq \Psi \leq \Psi_{\text {max }}
$$

Another inequality constraint is the reactive power provided by the SVC and it is taken as to be $0-20$ MVAR, eq. (22), which is $20 \%$ of total reactive demand corresponding to critical case. The optimal value of SVC is decided using the optimization techniques. Here, SVC is chosen as reactive power support device because of its ability to provide any amount of dynamic compensation to the system. Other device like STATCOM could have been suggested but its size is bulky as it has converter topology. Fixed capacitor is not suggested as it can lead to both under compensation or over compensation. Our focus was on reactive compensation amount and not on the device providing that amount of compensation. Any other device can also be used.

$$
Q_{G s h \text { i min }} \leq Q_{G s h i} \leq Q_{G s h \text { i } \max }
$$

While altering the loads it is to be noted that minimum Eigen value of load flow Jacobian should be greater than zero which means system is not operating near collapse point, this can be limited by taking eq. (23) as one of the inequality constraints,

$$
e i g[J]>0
$$

After satisfying all the constraints Effective Reactive Reserve can be calculated by following eq. (24)

$$
\Delta Q_{g i}^{r e s}=Q_{G i \max }-Q_{G i}{ }^{\xi}
$$

\section{METHODOLOGY}

The proposed approach to solve optimal reactive power compensation problem using Differential Evolution technique is described here under,
Step 2: Calculate L-index [25] value for all lines using eq. (25)

$$
L_{i j}=\frac{4\left\lfloor\left(P_{j} X_{i j}-Q_{j} R_{i j}\right)^{2}+\left(P_{j} R_{i j}+Q_{j} X_{i j}\right) V_{i}^{2}\right\rfloor}{V_{i}^{4}}
$$

Step 3: Rank the lines in descending order of L-Index and select one line with larger value as critical line for WTG application.

Step 4: Start the load flow with uncertain input values for load and WTG. Vary the parameters in each step.

Step 5: Compute minimum Eigen value of load flow Jacobian for each input alteration.

Step 6: Identify the case having least Eigen value (closer to $0)$.

Step 7: Calculate L-Index value for all the load buses [26], for most critical case using the formula (26)

$$
L=\max _{j \in \alpha_{L}}\left\{L_{j}\right\}=\max _{j \in \alpha_{L}}\left|1-\frac{\sum_{i \in \alpha_{G}} F_{j i} V_{i}}{V_{j}}\right|
$$

Step 8: Rank the buses in descending order of L-Index and select two buses with larger values as critical buses for placement of SVC. The SVC has been placed at bus number 9 and 14 as they are the weakest nodes in the system, thus reactive support is provided at them to boost the overall voltage profile of the system. The SVC placement has been decided by using equation (26).

Step 9: Generate population for SVC, (0-20) of size 'M' and distribute randomly,

$$
\begin{gathered}
S^{(0)}=\left[X_{1}^{(0)}, X_{2}^{(0)}, \ldots \ldots \ldots X_{M}^{(0)}\right] \\
X_{i}^{(0)}=\left[x_{i 1}^{(0)}, x_{i 2}^{(0)}, \ldots \ldots x_{i D}^{(0)}\right]^{T}
\end{gathered}
$$

$x_{i j}^{(0)}$ is obtained as follows,

$$
x_{i j}^{(0)}=x_{j, \min }+\left(x_{j, \max }-x_{j, \min }\right) \text { rand }_{j}
$$

$\mathrm{i}, \mathrm{j}=1,2,3 \ldots \mathrm{n}$

Step 1: Run the load flow for base case. 
Step 10: Compute the objective function for all the generations of the population,

$$
O=\min \sum_{N c o m p} x_{i}
$$

Step 11: Select all the feasible vectors.

Step 12: Add a scaled, randomly sampled, vector difference to a third vector as follows,

$$
\underline{V}_{i}^{(k)}=X_{r 1}^{(k)}+\zeta\left(X_{r 2}^{(k)}-X_{r 3}^{(k)}\right)
$$

Step 13: Compute the objective function for all favourable vectors

$$
O=\min \sum_{\text {Ncomp }} x_{i}
$$

Step 14: Control the number of parameter values which are copied from mutant vector using crossover probability ' $\mathrm{C}_{\mathrm{r}}$ '. Generate trial vectors ' $t_{i}$ ' as,

$$
t_{i, j}^{(k)}=\left\{\begin{array}{cr}
v_{i, j}^{(k)} & \text { if }\left(\text { rand }_{j} \leq C_{r} \text { or } j=j_{\text {rand }}\right) \\
x_{i, j}^{(k)} & \text { otherwise }
\end{array}\right.
$$

$v_{i, j}^{(k)}=x_{r 1, j}+\left(x_{j, \min }-x_{r 1, j}\right) \operatorname{rand}(0,1)$, if $v_{i, j}^{(k)} \leq x_{j, \min }$ $v_{i, j}^{(k)}=x_{r 1, j}+\left(x_{j, \max }-x_{r 1, j}\right) \operatorname{rand}(0,1)$, if $v_{i, j}^{(k)} \geq x_{j, \max }$

Step 15: Objective function is evaluated for target vector and trial vector,

$$
X_{i}^{(k+1)}=\left\{\begin{array}{lr}
t_{i}^{(k)} & \text { if } f\left(t_{i}^{(k)}\right) \leq f\left(X_{i}^{(k)}\right) \\
X_{i}^{(k)} & \text { otherwise }
\end{array}\right.
$$

Step 16: Increase the iteration count to $\mathrm{k}+1$ and move to step 12. Repeat the process until the stopping criteria are satisfied.

The flowchart for procedural approach used in this paper is shown in figure 12 .

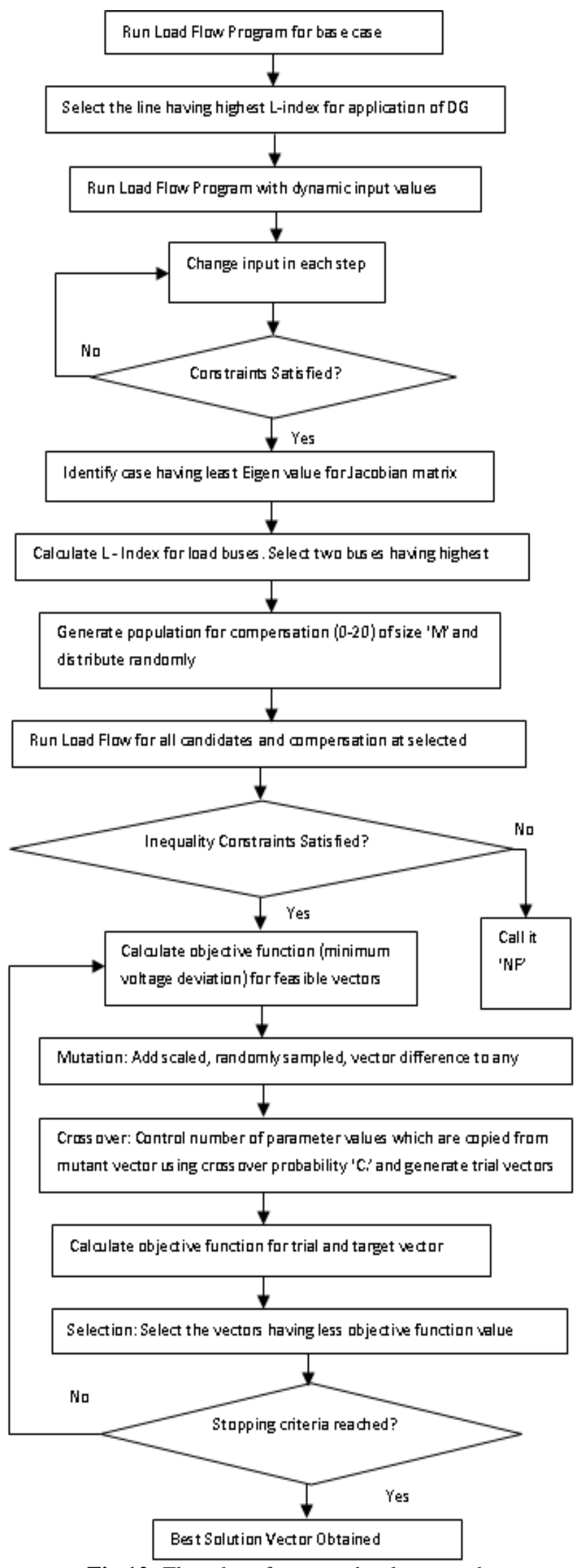

Fig 12: Flowchart for procedural approach 


\section{RESULTS AND DISSCUSSIONS}

The proposed methodology has been implemented for optimal sizing and placement of reactive compensation device, i.e. SVC, while accounting the dynamic alterations in WTG units and loads, on the IEEE - 14 bus system. The results have been compared with another optimization techniques to verify the effectiveness and applicability of proposed methodology. Dynamics alterations are made corresponding to the base case values and the most critical case, having least Eigen value, is identified and reactive compensation value is decided correspondingly. The range for Compensation is taken to be $0-20$ MVAR which is approximately $20 \%$ of the reactive load requirement corresponding to critical case. The desired range for load bus voltage is taken as $0.95-1.05$ P.U.

Buses 1, 2 and 3 have generators connected to them. Buses 6 and 8 have synchronous condensers connected to them. The rest of the buses are load buses. The test system has 20 branches, 14 buses and 11 distinct loads. The base MVA of the system is 100 . The complete data of this system is taken from [22]. The base case real load of the test system is 2.593 P.U. and reactive load is 0.736 P.U. Table 1 shows the load flow results corresponding to base case values. L - Index for lines [23] is used to identify the weakest tie in the system corresponding to base case for optimal placement of WTG units. Table 2 shows the value of $\mathrm{L}$ - Index corresponding to each line. Line 9 has the closest value to 1.0 , thus it is a critical line and corresponding buses i.e., bus 4 and 7 are selected for WTG units' placement. Load flow is run for each dynamic alteration in WTG and load variation. Change in minimum Eigen value of the load flow Jacobian matrix is plotted in figure 13. Eigen value is highest corresponding to $6^{\text {th }}$ alteration i.e., 0.5913 and load flow results are tabulated in table 3. For the healthy case real power loading is 2.304 P.U. and reactive power loading is 0.694 P.U. Eigen value is lowest corresponding to $26^{\text {th }}$ alteration i.e., 0.5681 and load flow results are tabulated in table 4 . For critical case real power loading is 2.698 P.U. and reactive power loading is 0.924 P.U. L - Index for buses [24] is used to identify weak buses in the system for critical case. The two buses having higher value of $\mathrm{L}-$ Index are the critical buses. The $\mathrm{L}-$ Index values are indicated in table 4 . Buses 9 and 14 are the critical nodes corresponding to critical case. These buses are selected for application of reactive compensation through SVC.

Table 1: Base Case results of IEEE-14 bus system Minimum Eigen value $=0.5881$

\begin{tabular}{|l|l|l|l|l|l|l|l|}
\hline $\begin{array}{l}\text { Bus } \\
\text { No. }\end{array}$ & $\begin{array}{l}\text { Type of } \\
\text { Bus }\end{array}$ & $\begin{array}{l}\text { Voltage } \\
\text { Magnitude } \\
\text { (p.u.) }\end{array}$ & $\begin{array}{l}\text { Angle } \\
\text { (Degree) }\end{array}$ & $\begin{array}{l}\text { Active } \\
\text { Load } \\
(\text { MW) }\end{array}$ & $\begin{array}{l}\text { Reactive } \\
\text { Load } \\
\text { (MVAR) }\end{array}$ & $\begin{array}{l}\text { Active } \\
\text { Generation } \\
(\text { MW) }\end{array}$ & $\begin{array}{l}\text { Reactive } \\
\text { Generation } \\
\text { (MVAR) }\end{array}$ \\
\hline 1 & 2 & 1.010 & 2.049 & 0.0 & 0.0 & 114.70 & 4.463 \\
\hline 2 & 1 & 1.000 & 0.000 & 21.7 & 12.7 & 133.50 & 31.32 \\
\hline 3 & 2 & 0.960 & -7.414 & 94.2 & 19.1 & 20.00 & 16.865 \\
\hline 4 & 0 & 0.960 & -5.987 & 47.8 & -3.9 & 0.0 & 0.000 \\
\hline 5 & 0 & 0.964 & -4.742 & 7.6 & 1.6 & 0.0 & 0.000 \\
\hline 6 & 2 & 1.000 & -11.036 & 11.2 & 7.5 & 0.0 & 17.433 \\
\hline 7 & 0 & 0.977 & -9.465 & 0.0 & 0.0 & 0.0 & 0.000 \\
\hline 8 & 2 & 1.000 & -9.465 & 0.0 & 0.0 & 0.0 & 13.049 \\
\hline 9 & 0 & 0.962 & -11.331 & 29.5 & 16.6 & 0.0 & 0.000 \\
\hline 10 & 0 & 0.961 & -11.605 & 9.0 & 5.8 & 0.0 & 0.000 \\
\hline 11 & 0 & 0.976 & -11.456 & 3.5 & 1.8 & 0.0 & 0.000 \\
\hline 12 & 0 & 0.982 & -12.009 & 6.1 & 1.6 & 0.0 & 0.000 \\
\hline 13 & 0 & 0.975 & -12.051 & 13.8 & 5.8 & 0.0 & 0.000 \\
\hline 14 & 0 & 0.948 & -12.831 & 14.9 & 5.0 & 0.0 & 0.000 \\
\hline Total & & & & 259.300 & 73.600 & 268.201 & 83.134 \\
\hline
\end{tabular}

Table 2: L-Index for Lines Corresponding to Base Case

\begin{tabular}{|l|l|l|l|l|l|l|l|l|l|l|}
\hline Line No. & 1 & 2 & 3 & 4 & 5 & 6 & 7 & $\mathbf{8}$ & 9 & 10 \\
\hline L - Index & 0.047 & 0.221 & 0.226 & 0.222 & 0.159 & 0.019 & 0.019 & $\mathbf{0 . 9 7 8}$ & 0.969 & 0.932 \\
\hline Line No. & 11 & 12 & 13 & 14 & 15 & 16 & 17 & 18 & 19 & 20 \\
\hline L - Index & 0.095 & 0.073 & 0.100 & 0.094 & 0.068 & 0.008 & 0.061 & 0.065 & 0.028 & 0.113 \\
\hline
\end{tabular}




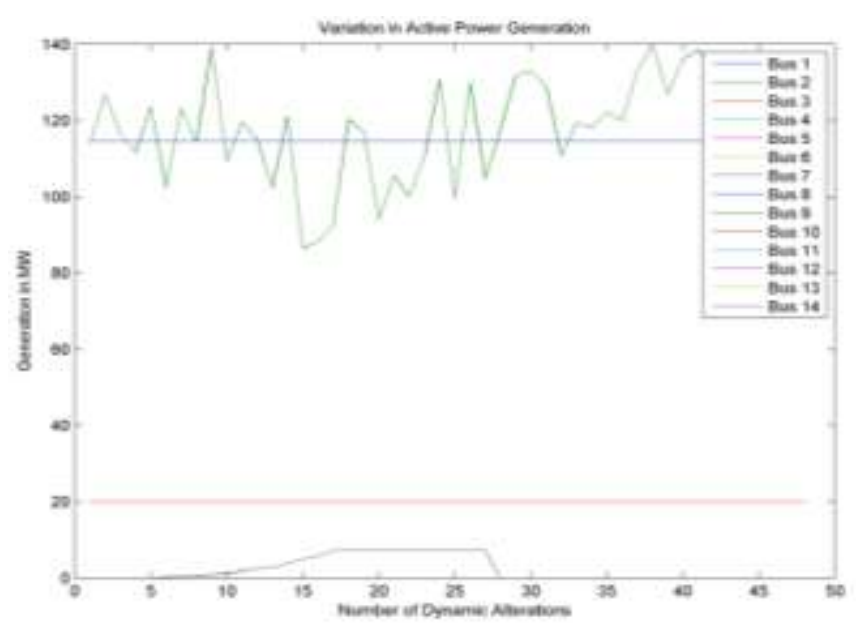

Fig 13: Variation in Active Generation at Different Buses

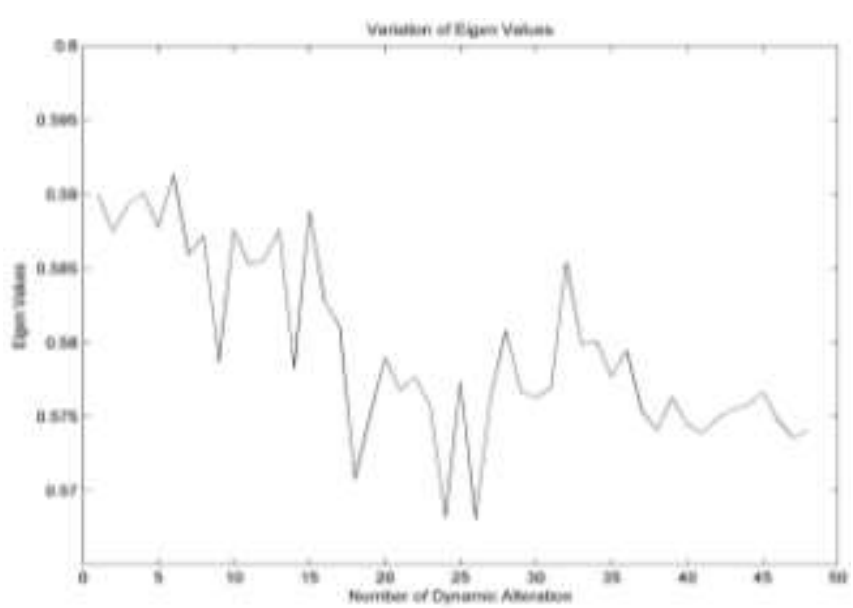

Fig. 14 Variation in Eigen Value for Alterations in WTG and Load

Table 3: Load Flow Results Corresponding to Healthy Case (Min Eigen value $=0.5913$ )

\begin{tabular}{|l|l|l|l|l|l|l|l|}
\hline $\begin{array}{l}\text { Bus } \\
\text { No. }\end{array}$ & $\begin{array}{l}\text { Voltage } \\
\text { Mag. (p.u.) }\end{array}$ & $\begin{array}{l}\text { Angle } \\
\text { (Degree) }\end{array}$ & $\begin{array}{l}\text { Active } \\
\text { Load (MW) }\end{array}$ & $\begin{array}{l}\text { Reactive } \\
\text { Load } \\
\text { (MVAR) }\end{array}$ & $\begin{array}{l}\text { Active Generation } \\
\text { (MW) }\end{array}$ & $\begin{array}{l}\text { Reactive Generation } \\
\text { (MVAR) }\end{array}$ & $\begin{array}{l}\text { L } \\
\text { Index }\end{array}$ \\
\hline 1 & 1.010 & 2.256 & 0.000 & 0.000 & 114.700 & 3.205 & - \\
\hline 2 & 1.000 & 0.000 & 21.700 & 12.700 & 102.439 & 42.150 & - \\
\hline 3 & 0.950 & -6.626 & 94.200 & 19.100 & 20.000 & 5.970 & - \\
\hline 4 & 0.961 & -4.765 & 26.356 & -3.579 & 0.230 & 0.000 & 0.0223 \\
\hline 5 & 0.965 & -3.776 & 7.705 & 1.600 & 0.000 & 0.000 & 0.0160 \\
\hline 6 & 0.990 & -9.537 & 11.200 & 7.500 & 0.000 & 8.635 & - \\
\hline 7 & 0.979 & -7.927 & 0.000 & 0.321 & 0.230 & 0.000 & 0.0350 \\
\hline 8 & 1.000 & -7.927 & 0.000 & 0.000 & 0.000 & 12.047 & - \\
\hline 9 & 0.965 & -9.637 & 29.500 & 16.600 & 0.000 & 0.000 & $\mathbf{0 . 0 6 4 7}$ \\
\hline 10 & 0.967 & -9.710 & 1.436 & 0.926 & 0.000 & 0.000 & 0.0562 \\
\hline 11 & 0.975 & -9.769 & 3.500 & 1.800 & 0.000 & 0.000 & 0.0329 \\
\hline 12 & 0.973 & -10.505 & 6.100 & 1.600 & 0.000 & 0.000 & 0.0273 \\
\hline 13 & 0.967 & -10.545 & 13.800 & 5.800 & 0.000 & 0.000 & 0.0359 \\
\hline 14 & 0.946 & -11.225 & 14.900 & 5.000 & 0.000 & 0.000 & $\mathbf{0 . 0 8 2 5}$ \\
\hline Total & & & 230.397 & 69.368 & 237.598 & 72.007 & \\
\hline
\end{tabular}

Table 4: Load Flow Results Corresponding to Critical Case ( Min Eigen value $=0.5681$ )

\begin{tabular}{|l|l|l|l|l|l|l|l|}
\hline $\begin{array}{l}\text { Bus } \\
\text { No. }\end{array}$ & $\begin{array}{l}\text { Voltage } \\
\text { Mag. (p.u.) }\end{array}$ & $\begin{array}{l}\text { Angle } \\
\text { (Degree) }\end{array}$ & $\begin{array}{l}\text { Active } \\
\text { Load (MW) }\end{array}$ & $\begin{array}{l}\text { Reactive } \\
\text { Load } \\
\text { (MVAR) }\end{array}$ & $\begin{array}{l}\text { Active Generation } \\
\text { (MW) }\end{array}$ & $\begin{array}{l}\text { Reactive Generation } \\
\text { (MVAR) }\end{array}$ & $\begin{array}{l}\text { L } \\
\text { Index }\end{array}$ \\
\hline 1 & 1.010 & 2.096 & 0.000 & 0.000 & 114.700 & 9.960 & - \\
\hline 2 & 1.000 & 0.000 & 21.700 & 12.700 & 129.924 & 53.098 & - \\
\hline 3 & 0.950 & -7.307 & 94.200 & 19.100 & 20.000 & 15.550 & - \\
\hline 4 & 0.944 & -5.652 & 59.488 & 6.080 & 0.000 & 0.000 & 0.0417 \\
\hline 5 & 0.952 & -4.446 & 8.236 & 1.600 & 0.000 & 0.000 & 0.0280 \\
\hline 6 & 0.970 & -10.717 & 11.200 & 7.500 & 0.000 & 11.149 & - \\
\hline 7 & 0.946 & -8.603 & 0.000 & 9.980 & 0.000 & 0.000 & 0.0538 \\
\hline 8 & 0.970 & -8.603 & 0.000 & 0.000 & 0.000 & 13.306 & - \\
\hline 9 & 0.933 & -10.717 & 29.500 & 16.600 & 0.000 & 0.000 & $\mathbf{0 . 0 8 6 8}$ \\
\hline 10 & 0.933 & -11.003 & 7.181 & 4.628 & 0.000 & 0.000 & 0.0805 \\
\hline 11 & 0.947 & -11.005 & 3.500 & 1.800 & 0.000 & 0.000 & 0.0453 \\
\hline 12 & 0.952 & -11.729 & 6.100 & 1.600 & 0.000 & 0.000 & 0.0299 \\
\hline 13 & 0.945 & -11.754 & 13.800 & 5.800 & 0.000 & 0.000 & 0.0403 \\
\hline 14 & 0.918 & -12.433 & 14.900 & 5.000 & 0.000 & 0.000 & $\mathbf{0 . 0 9 9 2}$ \\
\hline Total & & & 269.804 & 92.387 & 278.897 & 103.063 & \\
\hline
\end{tabular}


It can be observed that corresponding to critical case the voltage deviation is poor. So, one aim can be to improve the voltage profile at each bus. The $\mathrm{L}$ - Index value is approaching 1.0 for few buses. Thus, to improve the stability index, another aim can be to reduce its value to 0.0 . Alternatively aim can be to reduce the losses i.e., both active and reactive losses and increase the reactive reserve margin. But, here our objective was to enhance the voltage profile i.e., reduce the deviation in voltage. While focusing on reducing voltage deviation at $14^{\text {th }}$ bus especially, voltage profile at other load buses is also improved and simultaneously the losses have been reduced from those in the base case. This is clearly depicted in table 6, figure 16 and figure 17.

Initially, 200 random particles are generated of $0-20$ MVAR reactive compensation through SVC for both the selected buses. Maximum number of iterations are 60 . The particles that satisfy all the operating constraints are feasible solutions and further used in optimization process. The objective function is evaluated focusing on voltage at $14^{\text {th }}$ bus, as its voltage profile is the worst in base case.

\subsection{Results obtained by Differential Evolution}

Optimal value of compensation at the identified buses is obtained as Qsh9 = 19.920 MVAR and Qsh14 = 19.975 MVAR. Optimal value of objective function, i.e. minimum voltage deviation at the 14 th bus is 0.0938 . Time elapsed in computing the optimal value of compensation and objective function is 26.35 seconds. The best solution is obtained at 2nd iteration and no further improvement in value of objective function is observed.

\subsection{Results obtained by Black Hole Algorithm}

Optimal value of compensation at the identified buses is obtained as Qsh9 = 18.142 MVAR and Qsh14 = 19.129 MVAR. Optimal value of objective function, i.e. minimum voltage deviation at the 14 th bus is 0.1027 . Time elapsed in computing the optimal value of compensation and objective function is 9.87 seconds. The best solution is obtained at 7th iteration and no further improvement in value of objective function is observed.

\subsection{Results obtained by Particle Swarm Optimization}

Optimal value of compensation at the identified buses is obtained as Qsh9 = 19.400 MVAR and Qsh14 = 19.936 MVAR. Optimal value of objective function, i.e. minimum voltage deviation at the 14 th bus is 0.0888 . Time elapsed in computing the optimal value of compensation and objective function is 31.51 seconds.

The optimum value of compensation, value of objective function and time elapsed in computation for each optimization technique is shown in table 5. The convergence of the objective function is depicted in figure 15. The comparison in voltage magnitude, reactive compensation, Eigen value and losses is presented in table 6. Bar graph representation of voltage profile for critical case and after applying compensation consequent to each optimization technique is given in figure 16. Bar graph representation of loss variation for critical case and after applying compensation consequent to each optimization technique is given in figure 17. The enhancement of stability in voltage can be very well deduced from the increase in reactive reserve margins depicted in figure 18 , as from generator end the voltage stability is directly related to reactive reserves available at the generators [29].

From the results, it can be confirmed that voltage magnitude is enhanced at all the weak buses and simultaneously the losses are also minimized. Overall results, agreeing with objective function, compensation value, time elapsed in computation, voltage profile enhancement and loss minimization are obtained from Differential Evolution, Black Hole Algorithm and Particle Swarm Optimization. But the best results are obtained corresponding to the Differential Evolution.

Table 5: Optimal Compensation at Selected Buses Using Different Optimization Techniques

\begin{tabular}{|l|l|l|l|l|}
\hline Sr. No. & Selected buses for compensation & \multicolumn{2}{l|}{ Amount of compensation using different Optimization Technique } \\
\cline { 3 - 5 } & & $\boldsymbol{D E}$ & $\boldsymbol{B H A}$ & PSO \\
\hline $\mathbf{1}$ & 9 & 19.920 & 18.142 & 19.400 \\
\hline $\mathbf{2}$ & 14 & 19.975 & 19.129 & 19.936 \\
\hline Total Compensation 'MVAR' & 39.895 & 37.271 & 39.336 \\
\hline Value of objective function & 0.0938 & 0.1027 & 0.0888 \\
\hline Time elapsed in computation 'sec.' & 26.351822 & 9.870384 & 31.511625 \\
\hline
\end{tabular}




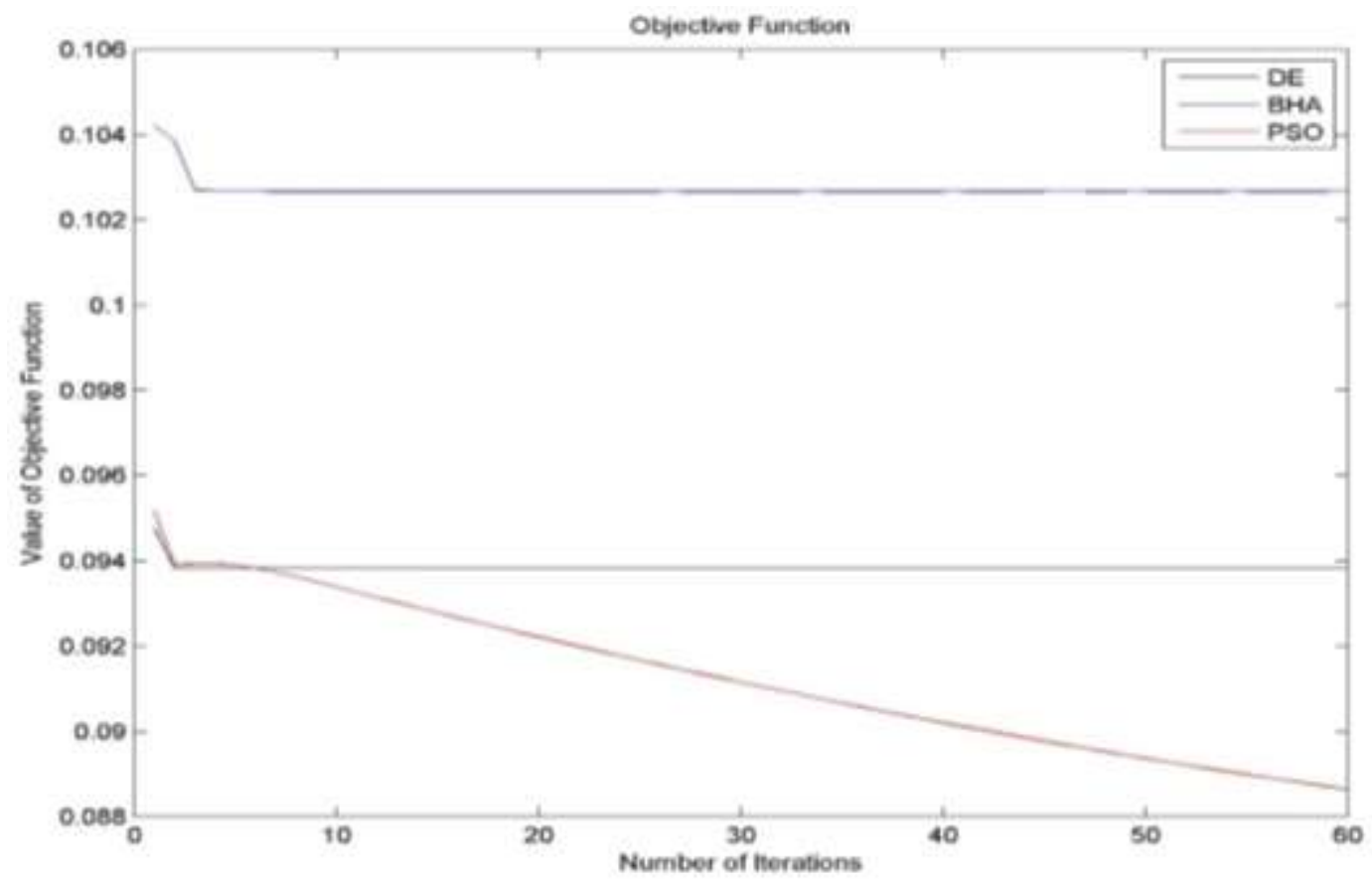

Fig 15: Convergence of Objective Function for Various Optimization Techniques

Table 6: Voltage Profile for Critical Case and After Optimization

\begin{tabular}{|c|c|c|c|c|c|c|c|c|}
\hline \multirow[t]{3}{*}{ Bus No. } & \multirow{2}{*}{\multicolumn{2}{|c|}{$\begin{array}{l}\text { Before Optimization } \\
\text { Critical Case }\end{array}$}} & \multicolumn{6}{|c|}{ After Optimization } \\
\hline & & & \multicolumn{2}{|l|}{$\mathbf{D E}$} & \multicolumn{2}{|l|}{ BHA } & \multicolumn{2}{|l|}{ PSO } \\
\hline & $\begin{array}{l}\text { Voltage } \\
\text { (pu) }\end{array}$ & SVC (MVAR) & $\begin{array}{l}\text { Voltage } \\
\text { (pu) }\end{array}$ & $\begin{array}{l}\text { SVC } \\
\text { (MVAR) }\end{array}$ & $\begin{array}{l}\text { Voltage } \\
\text { (pu) }\end{array}$ & $\begin{array}{l}\text { SVC } \\
\text { (MVAR) }\end{array}$ & $\begin{array}{l}\text { Voltage } \\
\text { (pu) }\end{array}$ & $\begin{array}{l}\text { SVC } \\
\text { (MVAR) }\end{array}$ \\
\hline 1 & 1.010 & 0.000 & 1.010 & 0.000 & 1.010 & 0.000 & 1.010 & 0.000 \\
\hline 2 & 1.000 & 0.000 & 1.000 & 0.000 & 1.000 & 0.000 & 1.000 & 0.000 \\
\hline 3 & 0.950 & 0.000 & 0.950 & 0.000 & 0.950 & 0.000 & 0.950 & 0.000 \\
\hline 4 & 0.944 & 0.000 & 0.970 & 0.000 & 0.970 & 0.000 & 0.970 & 0.000 \\
\hline 5 & 0.952 & 0.000 & 0.973 & 0.000 & 0.973 & 0.000 & 0.973 & 0.000 \\
\hline 6 & 0.970 & 0.000 & 1.010 & 0.000 & 1.010 & 0.000 & 1.010 & 0.000 \\
\hline 7 & 0.946 & 0.000 & 1.001 & 0.000 & 1.000 & 0.000 & 1.001 & 0.000 \\
\hline 8 & 0.970 & 0.000 & 1.000 & 0.000 & 1.000 & 0.000 & 1.000 & 0.000 \\
\hline 9 & 0.933 & 0.000 & 1.008 & 19.920 & 1.006 & 18.142 & 1.008 & 19.400 \\
\hline 10 & 0.933 & 0.000 & 1.006 & 0.000 & 1.004 & 0.000 & 1.006 & 0.000 \\
\hline 11 & 0.947 & 0.000 & 1.005 & 0.000 & 1.004 & 0.000 & 1.005 & 0.000 \\
\hline 12 & 0.952 & 0.000 & 0.999 & 0.000 & 0.999 & 0.000 & 0.999 & 0.000 \\
\hline 13 & 0.945 & 0.000 & 0.999 & 0.000 & 0.998 & 0.000 & 0.998 & 0.000 \\
\hline 14 & 0.918 & 0.000 & 1.015 & 19.996 & 1.013 & 19.129 & 1.015 & 19.936 \\
\hline Eigen Value & \multicolumn{2}{|l|}{0.5681} & \multicolumn{2}{|l|}{0.6088} & \multicolumn{2}{|l|}{0.6081} & \multicolumn{2}{|l|}{0.6086} \\
\hline Active Loss (MW) & \multicolumn{2}{|l|}{9.093} & \multicolumn{2}{|l|}{7.116} & \multicolumn{2}{|l|}{7.099} & \multicolumn{2}{|l|}{7.115} \\
\hline Reactive Loss (MVAR) & \multicolumn{2}{|l|}{10.676} & \multicolumn{2}{|l|}{0.972} & \multicolumn{2}{|l|}{0.919} & \multicolumn{2}{|l|}{0.966} \\
\hline
\end{tabular}




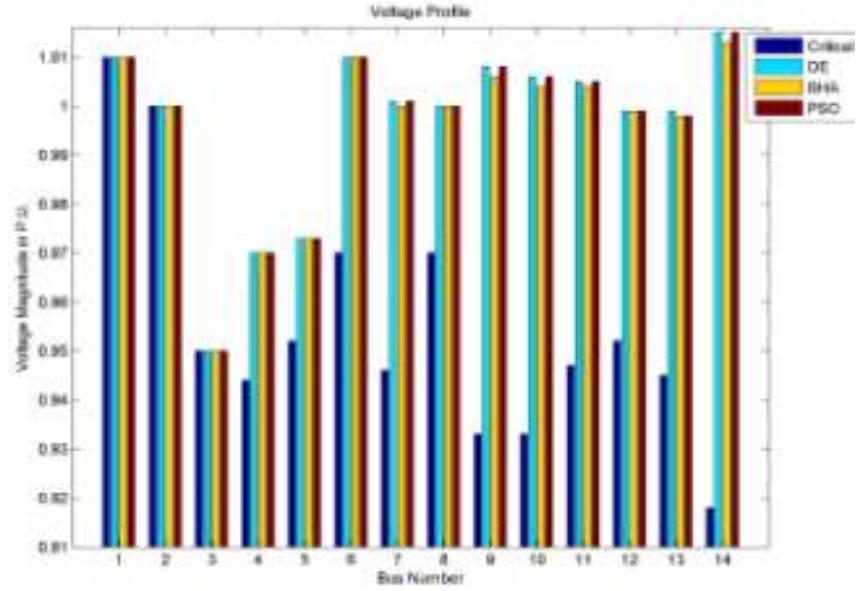

Fig 16: Voltage Profile for Critical Case and After Optimization

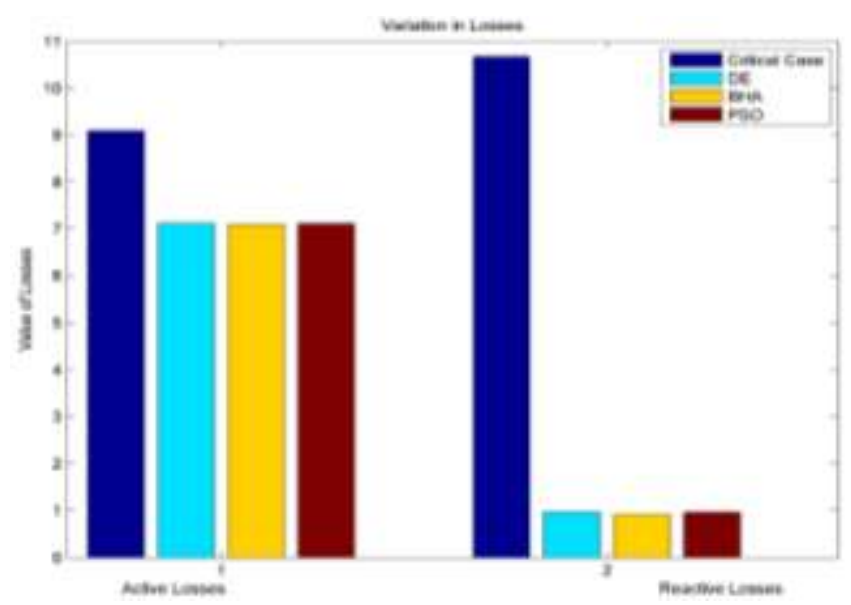

Fig 17: Losses Corresponding to Critical Case and After Optimization

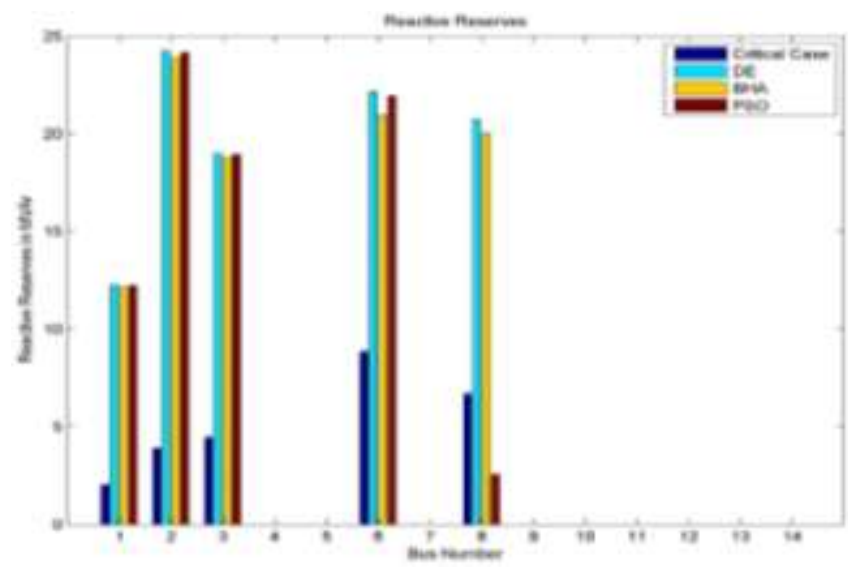

Fig 18: Reactive Reserve Variation Corresponding to Critical Case and After Optimization

\section{CONCLUSION}

In this paper, the method for optimal setting of reactive power control variables with the objective function of minimum voltage deviation under DG and load uncertainties was proposed. The proposed algorithm has been applied to practical IEEE 14- bus system. The dynamics at the consumer end have been accounted in terms of DG and load uncertainties. Differential Evolution technique is used to solve complex reactive power optimization problem. The main objective is to minimize the voltage deviation and losses in the network, while satisfying all the power system operation constraints. The power flow by Newton-Raphson method and Differential Evolution have been coded using MATLAB-2010. The results show that Differential Evolution always lead to a satisfactory result. The results obtained by DE have been compared to the results obtained by BHA and PSO to validate its accuracy and effectiveness. Thus, it can be endorsed that results obtained by DE can be used to solve large scale optimization problems.

\section{REFERENCES}

[1] F. Owen Hoffman, "A Guide For Uncertainty Analysis in Dose and Risk Assessments Related to Environmental Contamination", National Council on Radiation Protection and Measurements 1996, ISBN 0-929600-52-5J. Clerk Maxwell, A Treatise on Electricity and Magnetism, 3rd ed., vol. 2. Oxford: Clarendon, pp.68-73, 1996.

[2] J.C. Heltona, F.J. Davisb, "Latin Hypercube Sampling and the Propagation of Uncertainty in Analyses of Complex Systems", Reliability Engineering and System Safety 81, pp. 23-69, February 2003.

[3] W. Sweet, "Tighter Regional Regulation Needed of Power Grids that is the Unanimous Conclusion of Experts on The Great 2003 Blackout", IEEE Spectrum, Oct. 2003.

[4] C. Rajagopalan , B.C. lesieutre, P.W. Sauer, M.A. Pai, "Dynamic Aspects of Voltage/Power Characteristics", IEEE Transactions on Power Systems, pp. 990-1000, 1992.

[5] L. Byongjun, V Ajjarapu, “A Piecewise Global Small Disturbance Voltage-Stability Analysis of Structure Preserving Power System Models", IEEE Transactions on Power Sysems, pp. 1963-1971, 1995.

[6] M.M. Begovic, A.G Phadke, "Dynamic Simulation of Voltage Collapse", IEEE Transaction on Power Systems, pp. 1529-1534, 1990.

[7] J. Deuse, M. Stubbe, "Dynamic Simulation of Voltage Collapses", IEEE Transactions on Power Systems, pp. 894-904, 1993.

[8] Ian A. Hiskens, Jassim Alseddiqui, “Approximation and Uncertainty in Power System Dynamic Simulation", IEEE Transactions on Power Systems, vol. 21, no. 4, pp.1808-1820, 2006.

[9] M. Ali, M. Pant, A. Abraham, "A Modified Differential Evolution Algorithm and its Application to Engineering Problems", 2009 International Conference of Soft Computing and Pattern Recognition, IEEE Computer Society, 987-0-76953879-2/09, 2009. 
[10] A. Hatamlou, "Blackhole: A New Heuristic Optimization Approach for Data Clustering", Information Sciences Elsevier, 222, 175-184, 2013.

[11] J.F. Zhang, C.T. Tse1 K.W. Wang, C.Y. Chung, "Voltage Stability Analysis Considering the Uncertainties of Dynamic Load Parameters", IET Gener. Transm. Distrib., vol. 3, issue. 10, pp. 941948, 2009.

[12] Y.G. Zeng, G. Berizzi, P. Marannino, "Voltage Stability Analysis Considering Dynamic Load Model", Proc. Fourth Int. Conf. Advances in Power System Control, Operation and Management, APSCOM-97, Hong Kong, pp. 396-401, November 1997.

[13] Y.V Makarov,V.A. Maslennikov, D.J. Hill, "Revealing Loads Having the Biggest Influence on Power System Small Disturbance Stability", IEEE Trans. Power Systems, pp. 2018-2023, 1996.

[14] P. Zhang, S. T. Lee, "Probabilistic Load Flow Computation Using the Method Of Combined Cumulants And Gram-Charlier Expansion", IEEE Trans Power Systems, vol. 19, iss. 1, pp. 676 - 682, Feb. 2004.

[15] D. Karlsson, D.J. Hill, "Modelling and Identification of Nonlinear Dynamic Loads in Power Systems", IEEE Transaction on Power Systems, pp. 157-166, 1994.

[16] W. Xu, Y. Mansour, "Voltage Stability Analysis Using Generic Dynamic Load Models", IEEE Transaction on Power Systems, pp. 479-493, 1994.

[17] R. Karki, PoHu, R. Billinton, "A Simplified Wind Power Generation Model for Reliability Evaluation" IEEE Transactions on Energy Conversion, vol. 21, no. 2, pp. 533-540, 2006.

[18] R. Billinton, Yi Gao ,"Multistate Wind Energy Conversion System Models for Adequacy Assessment of Generating Systems Incorporating Wind Energy" IEEE Transactions on Energy Conversion, vol. 23, pp. 163-170, 2008.

[19] P.A.Ruiz, P.W. Sauer, "Reactive Power Reserve Issues", IEEE Transaction on Power Systems, pp. 439-445, 2006.

[20] R. Eberhart, J. Kennedy, "A New Optimizer Using Particle Swarm Theory", Sixth International Symposium on Micro Machine and Human Science, pp. 39-43, 1995.

[21] Efren Mezura-Montes, Margarita Reyes-Sierra, Carlos A. Coello, "Multi- Objective Optimization Using Differential Evolution: A Survey of the Stateof-the-Art", IEEE Transactions on Evolutionary Computation, vol. 15, 2012.

[22] R.D. Christie, "Power System Test Case Archive", University of Washington, Department of Electrical Engineering, Retrieved March 10, 2011 from http://www.ee.washington.edu/research/pstca/index.h tml

[23] W. Sheng, Ke-Yan Liu, Y. Liu, X. Meng, Y. Li, "Optimal Placement and Sizing of Distributed Generation via an Improved Non-dominated Sorting
Genetic Algorithm II", IEEE Transactions on Power Delivery, vol. 30, issue: 2, pp. 569 - 578, April 2015.

[24] P. Kessel, H. Glavitsch, "Estimating the Voltage Stability of a Power System", IEEE Power Engineering Review, vol. PER-6, issue: 7, pp. 72, July 1986.

[25] G B Jasmon, L H C C Lee, "Distribution Network Reduction for Voltage Stability Analysis and Load Flow Calculations", Electrical Power and Energy Systems, vol. 13, issue: 1, pp. 1-3, 1991.

[26] P. Kessel, H. Glavitsch, "Estimating the Voltage Stability of a Power System", IEEE Power Engineering Review, vol. PER-6, issue: 7, pp. 72, 1986.

[27] J. Zhu, "Optimization of Power System Operation", John Wiley Publication, 2009.

[28] H. Yu, C. Y. Chung, K. P. Wong, J. H. Zhang, “A Chance Constrained Transmission Network Expansion Planning Method With Consideration of Load and Wind Farm Uncertainties", IEEE Transactions On Power Systems, vol. 24, no. 3, Aug. 2009.

[29] P.A.Ruiz, P.W. Sauer, "Reactive Power Reserve issues", $38^{\text {th }}$ North American Power Symposium, pp. 163-170, March 2008. 